\title{
Extracontractual referrals in first three months of NHS reforms
}

\author{
Barbara Ghodse, Salman Rawaf
}

Abstract

Objective-To describe the extracontractual referrals of residents of Merton and Sutton Health Authority during the first three months of the NHS reforms in terms of the nature of the referral (elective or emergency), the specialty referred to, and the source of and reason for referral.

Design-Descriptive analysis of all extracontractual referrals submitted to the health authority between 1 April and 30 June 1991.

Setting-Merton and Sutton Health Authority.

Results-247 extracontractual referrals were notified to Merton and Sutton Health Authority; 83 invoices for emergency treatment and 109 elective referrals were authorised at a total cost of $\$ 190000$. Of the elective referrals, 59 were to ear, nose, and throat; orthopaedic; or general surgery departments. Local general practitioners made only two thirds of the elective referrals, at least 15 of which were made at the patient's request. Four admissions accounted for a quarter of the total cost of the emergency admissions.

Conclusions-Extracontractual referrals are unpredictable in terms of both their number and their cost. They provide a necessary safeguard for patient and general practitioner choice at the price of a considerable administrative workload. The fact that these referrals are income generating for providers means that additional safeguards may be necessary to prevent abuse of the system.

\section{Introduction}

With the introduction of contracting for health care as part of the NHS reforms, 'special arrangements have been made for patients who require treatment outside the contracts arranged by their health authority. A mechanism has been devised for extracontractual referral to permit flexibility of referral by general practitioners and to allow for patients needing emergency inpatient treatment when they are away from home. ${ }^{2}$ In comparison with the security and stability of block contracts, extracontractual referrals are unpredictable, in terms of both their number and their cost, and therefore cause considerable anxiety to purchasing authorities. In this paper we describe the extracontractual referrals of residents in Merton and Sutton Health Authority during the first three months of the new system.

Merton and Sutton are two outer, south London boroughs. There are pockets of deprivation in the north of the district, as well as areas of conspicuous affluence. A total of 165 general practitioners work in 66 practices. Most hospital care is provided by St Helier NHS Trust, an associated teaching hospital, and by St George's Hospital, a teaching hospital which lies just outside the health authority's boundary. Acute mental illness services are provided by Sutton and Springfield Hospitals.

Although block contracts for acute services have been agreed with 18 providers, including all but two of the London teaching hospitals, the size of the resident population $(340000)$ and its mobility mean that there have already been a considerable number of extracontractual referrals. This is the first account of the new system from the viewpoint of a purchaser, and highlights several issues that warrant further discussion.

\section{Method}

All notifications of extracontractual referrals received by Merton and Sutton Health Authority between 1 April and 30 June inclusively have been included. They can be divided into two types: firstly, requests for authorisation to proceed with elective treatment - in other words, an assurance that the hospital will be paid for treating the patient (elective extracontractual referrals); and, secondly, notifications of emergency admissions (emergency extracontractual referrals). Health authorities have to pay for the emergency inpatient treatment of their residents, and notification of admission by the provider is not mandatory; thus the first indication of an emergency admission is likely to be the arrival of an invoice.

We analysed extracontractual referrals to establish the specialty to which each referral was made and, in the case of elective referrals, the referring agency. Reasons for referral were explored with local general practitioners, who had accepted a policy that they may be contacted to discuss their extracontractual referrals. The cost of extracontractual treatment was calculated.

\section{Results}

In the course of the three months 247 extracontractual referrals were notified to Merton and Sutton Health Authority. Of the 192 for which payment was made or treatment authorised, $109(57 \%)$ were elective and $83(43 \%)$ were emergencies. We are awaiting further information on 20 referrals, and 35 $(14 \%)$ were refused or cancelled.

\section{EMERGENCY EXTRACONTRACTUAL REFERRALS}

The figure of 83 emergency extracontractual referrals during three months must be regarded as a minimum figure. Advance notification of a further 12 emergency admissions has already been received and more invoices relating to this period are arriving daily. These 83 emergencies were notified by 41 different hospitals; 22 of the patients were admitted to hospitals in south coast resort towns (about 95-110 km from Merton and Sutton). The table gives the specialty to which each referral was made.

Forty one (49\%) of the patients who were emergency admissions stayed in hospital for two days or less, with six being admitted and discharged on the same day and 19 being discharged the day after admission. Three patients were detained for more than six weeks.

The cost of 83 emergency referrals was $£ 119308$. Four admissions accounted for $24 \%$ ( $\$ 28524)$ of this expenditure: a mother who delivered twins who needed neonatal intensive care cots; two patients with mental illness; and one intensive care patient. The average cost of an emergency admission was £1437 (range £117$£ 16000)$.

\section{ELECTIVE EXTRACONTRACTUAL REFERRALS}

The 109 requests for authorisation of elective extracontractual referrals were submitted by hospitals in 35 different health authorities in nine regions. Some 
requested retrospective authorisation for patients already admitted; some were for treatment in the months ahead. Forty referrals were for inpatient care; 13 for day care; and 56 for outpatient consultation.

More than half of all elective extracontractual referrals were to ear, nose, and throat; orthopaedic; or general surgery departments (table). Nine referrals were made by dentists, two were made by sports medicine therapists, and three were tertiary referrals (a referral made by a hospital consultant to another hospital where there is no contract). According to the authorisation request forms, the remaining 95 referrals were made by the patients' general practitioners, 79 of whom were local, eight were "fringe" practitioners with a proportion of Merton and Sutton residents on their lists, and eight were located a long way away. No individual general practitioner or practice made extracontractual referrals more than occasionally.

Inquiry to 34 local general practitioners about their reason for making extracontractual referrals disclosed that it was not because of dissatisfaction with local or other contracted services. In 15 cases it was at the patient's request, sometimes for a second opinion and sometimes for reasons of personal convenience; in 12 cases there was a longstanding association with a particular hospital, often due to a much earlier tertiary referral; in one case the patient was referred to a female surgeon for breast surgery; and in one case the referral, at the patient's request, was to a surgeon prepared to carry out a total hip replacement on a Jehovah's Witness without a blood transfusion. In at least six cases the person currently registered as the patient's general practitioner had not personally referred the patient; this occurred in four cases because the patient had only recently moved on to the current general practitioner's list. The cost of the 109 elective referrals was $£ 70728$; the average cost was $£ 649$ (range $£ 25-£ 6702)$.

\section{REFUSALS}

Twenty one of the 35 extracontractual referrals that were refused or cancelled related to patients who were not residents of Merton and Sutton and four to patients of fundholding practices. Three patients chose to be treated privately, and in two cases the general practitioner had not made the referral personally and was unwilling for it to go ahead. Three requests for elective treatment were refused because authorisation was sought retrospectively; in one case the wait for treatment was unacceptably long; and in one case treatment became unnecessary.

\section{Discussion}

This study covers only a short time period at the start of the new system. The data presented here may therefore not be representative. Nevertheless, the study sheds some light on how the system is working. For example, it confirms the unpredictable nature of extracontractual referrals. In part this is due to the nature of emergencies, but unpredictability is increased by the lack of historical data about outpatient activity so that there is no way of knowing how many outpatient extracontractual referrals are to be expected. Although they are usually comparatively cheap, authorisation of outpatient consultations causes further uncertainty because of the open ended nature of future commitments.

In this context the speech made by the Parliamentary Secretary at the Department of Health, Baroness Hooper, at a seminar at the Institute of Health Service Management about the medical treatment of European Community nationals is of interest. European Community nationals receive all emergency and outpatient treatment in the United Kingdom free of charge (Baroness Hooper, DoH press release H91/114, 13
Number of elective and emergency extracontractual referrals made from 1 April to 30 Fune by specialty

\begin{tabular}{llc}
\hline Specialty & $\begin{array}{l}\text { Flective } \\
\text { referrals }\end{array}$ & $\begin{array}{c}\text { Emergency } \\
\text { referrals }\end{array}$ \\
\hline
\end{tabular}

Ear, nose, and throat surgery

Orthopaedics

General surgery

Dentistry

Gynaecology

Medicine

Rheumatolog

Paediatrics

Mental illness

Ophthalmology

Neurology

Obstetrics

Plastic surgery

Urology

Geriatrics

Other

30
17

Other

Total

109

19
12

25

8

2

5
4

4
4

1

4

2
3

2

83

March 1991). If United Kingdom citizens were treated similarly, without charge to the health authority of residence, the administrative burden of authorising extracontractual referrals would be substantially reduced.

A surprisingly large proportion of elective extracontractual referrals (33\%) had not been made by a general practitioner from Merton and Sutton district. Sometimes this was because the patient had moved to the district since attendance at the hospital had started, and sometimes because of referral by other health care professionals. Some patients attend general practices and dental practices at considerable distance from their homes and their referral is more likely to be extracontractual. It is clear that many extracontractual referrals are made in response to patients' requests.

Requests for authorisation were received from distant provider units which identified Merton and Sutton residents on their waiting lists. These commonly involved orthopaedic patients, for whom there is traditionally a long waiting time, and of the first 30 requests for authorisation for elective treatment, 11 were for orthopaedic treatment, with eight of these for inpatient or day case care. This raises the question of whether there has been a selective culling of waiting lists with earlier admission of extracontractual patients whose treatment will attract additional payment. While there has been considerable publicity about the emergence of a two tier health service with shorter waiting times for the patients of fundholding general practitioners, ${ }^{3.5}$ little attention seems to have been paid to the possibility of double waiting lists - one for block contract patients and one for extracontractual patients.

Although emergency extracontractual referrals are theoretically simpler to deal with than elective ones, areas of concern have already emerged. Firstly, from the distant viewpoint of a purchasing authority, it is not possible to establish whether an emergency admission, which is income generating for the provider, was necessary or whether the case could have been dealt with equally well within the accident and emergency department. Already, the number of invoices received for emergency treatment is double the figure projected from analysis of previous years' activity. As an emergency admission may last less than a day but may cost more than $£ 3800$ some system of audit, perhaps carried out by the host health authority, may be necessary to protect public resources.

Secondly, there is the question of when emergency treatment, which can be carried out without prior authorisation, should be considered completed and gives way to elective treatment, which requires authorisation. A similar difficulty arises in relation to when an admission can be considered a readmission, requiring additional payment, and when it should be 
considered as part of the original episode of care. For example, should the health authority pay once, twice, or three times for a patient who was originally admitted as an emergency with pleurisy, then readmitted for bronchoscopy, then admitted again for a chest drain procedure-all within the space of one month? In such cases providers and purchasers are likely to have different perspectives.

It seems likely that dealing with extracontractual referrals will always take a disproportionate amount of time because it involves a large number of cases, each handled individually. With the new emphasis on the role of health authorities in promoting the health of populations, however, such referrals safeguard the rights of the individual against the rigidity of contracts that have been placed in the interest of the public health and provide a fascinating insight into the sociodynamics of referral patterns.

1 Secretaries of State for Health, Wales, Northern Ireland, and Scotland. Working for patients. London: HMSO, 1989. (Cmnd 555.)

2 NHS Management Executive. Charging for extra contractual referral. London: Department of Health 1990. (Circular FDL(90)34.)

3 Drummond M, Crump B, Hawkes R, Marchment M. General practice fundholding. $B M 7$ 1990;301:1288-9.

4 Tucker WFG, Scott PVS. General practice fundholding. BMf 1991;302:117.

5 Beecham L. Yes, Prime Minister, it is underfunding. BMf 1991;302:1108-9.

(Accepted 23 fuly 1991)

\title{
Dealing with extracontractual referrals
}

\author{
J D Williamson
}

\begin{abstract}
Objective-To describe the mechanism established by Richmond, Twickenham, and Roehampton Health Authority to manage extracontractual referral requests made on behalf of its resident population and to examine its working in the first three months of the new arrangements.

Design-Description of the procedures for managing extracontractual referrals and the decisions made on requests submitted to the district health authority between 1 April and 30 June 1991.

Results -235 requests were submitted, 79 for emergency care. 156 requests were clearly for elective treatments and, of these, 61 were ultimately refused, 20 because the district health authority was not liable to pay. Of the remaining 41,17 were appealed successfully and three unsuccessfully. More than half of the elective extracontractual referrals correctly submitted were to either orthopaedics, general surgery, oral surgery, gynaecology, or plastic surgery. Overall, the district health authority approved three quarters of the requests for which it would be financially liable; this was the predicted workload for the period.

Conclusions-The management of extracontractual referral requests is complex and time consuming for clinicians and managers alike. Patient choice is clearly being limited to some extent, but this is necessary if the number of requests is not to exceed the levels on which funding is based.
\end{abstract}

\section{Introduction}

The way that district health authorities react to requests for funding care in provider units not covered by a contract will determine whether money follows the patients or patients follow the money.

The government's view is quite clear. The general practitioner should be free to refer patients anywhere, secure in the knowledge that there is finance available. On the other hand, the district health authority is accountable for its expenditure and cannot merely reflect individual practitioners' wishes regardless of their effect on other patient services. The synthesis of these apparently contradictory statements means that patients can go where they like, but the health authority may not pay.

The government has made it clear that purchasing authorities should have firm contracts with all provider units offering a significant service to their resident population. This we have interpreted as a total workload of more than 50 inpatient or day cases (around
$£ 100000)$ a year, or fewer if the average cost per case exceeds $£ 20000$. In most districts this would mean tying up about $95 \%$ of the health authority's financial resource in contracts, leaving only a small amount for extracontractual referrals.

\section{Financial issues}

Extracontractual referrals fall into three main categories: emergencies, elective secondary care, and elective tertiary care. Little research has been done, but a general survey of our last three years' data suggests that roughly a half of all referrals will be emergencies and a quarter will be referrals for tertiary care. The prudent purchasing authority will divide its extracontractual referral contingency (around 5\%) to reflect this; thus less than $2 \%$ of its financial resource is likely to be available to support non-emergency (or elective) referrals by general practitioners. This marginal amount removes from both the funding authority and the referring clinician the flexibility implicit in "the market." The manoeuvrability that does exist may well be progressively reduced as the larger contractors offer either a lower cost per case or an improved quality of care in return for an increased workload. Financial and managerial pressure will inevitably squeeze extracontractual referrals as time goes by.

Three other issues may effect the availability of funding for extracontractual referrals. The first is the statutory requirement that purchasing authorities pay the excess costs of hospital care arranged by any general practitioner fundholder when these exceed $£ 5000$ for any individual patient in any one year. The number of such cases is not yet known. Secondly, there is the need to consider possible spending on rehabilitation or continuing care, with community care being implemented in 1993. Thirdly, there is the whole question of overspending. The existence of an agreement or contract between a purchaser or provider does not mean that all health needs are automatically met. Although many contracts have banded workload targets to take account of fluctuations in demand, it is by no means impossible that there should be unexpectedly high workloads which cannot be diverted to other contractors and will require additional funds. Because these three extras will probably have to be met from district reserves, the district contingency needs to be divided into several categories, none of which will be large (box). The risk of a queue developing for the money not allocated in the elective secondary care category is enormous. 